\title{
Incidencia de bacilos Gram (-) productores de Carbapenemasas en el Hospital Escuela "Gral. José F. de San Martín" de la ciudad de Corrientes, Argentina, durante el mes de agosto del 2018
}

Gómez Capará De Aguirre, Leyla Guadalupe ${ }^{1}$; Rausch, Andrea Luciana ${ }^{2}$

\section{Resumen}

Objetivo: Determinar el porcentaje de enterobacterias productoras de carbapenemasas en infecciones y colonizaciones de adultos, y contribuir con datos estadísticos del hospital en la regiónl.

Materiales y métodos: Se estudiaron 386 muestras clínicas de pacientes atendidos en el Hospital Escuela "Gral. José F. de San Martín", Ciudad de Corrientes, durante el mes de agosto del 2018. Los métodos utilizados para la detección de carbapenemasas se realizaron siguiendo los protocolos descritos por el Servicio Antimicrobianos, Laboratorio Nacional de Referencia en Antimicrobianos, INEI-ANLIS "Dr.
Carlos G. Malbrán"; como ser: Blue Carba, Triton Hodge Test (THT) y Método de inhibición de los carbapenemes (mCim).

Se identificaron 70 Enterobacterias $(18,13 \%)$ y 25 Bacilos no fermentadores $(6,48 \%)$. Del total de Enterobacterias identificadas, el $30 \%$ fueron productores de carbapenemasas, de los cuales el 20\% del tipo KPC, el 7.14\% del tipo Sme, el $1.43 \%$ del tipo NDM y el $1.43 \%$ restante del tipo OXA-163. Con respecto a los Bacilos No fermentadores identificados, el $40 \%$ son Pseudomonas aeruginosa, el $8 \%$ Stenotrophomona maltophilia y el 52\% restante Acinetobacter spp. De ésta última todas fueron productoras de carbapenemasas tipo OXA-Aci.

1 Bioquímica, Especialista en Bacteriología Clínica - Facultad de Medicina- Universidad Nacional del Nordeste. Bioquímica de planta de la Sección Microbiología y Parasitología del Hospital Escuela "Gral. José Fco. de San Martín”. Rivadavia 1250, Corrientes (Capital).Email: leylagomezcapara@yahoo.com.ar

2 Alumna avanzada de la Carrera de Bioquímica de la Facultad de Ciencias Exactas y Naturales y Agrimensuras (UNNE).Email: lucianarausch94@gmail.com 
Discusión y conclusiones: Se obtuvo, durante el mes de agosto del 2018, un importante porcentaje de Enterobacterias productoras de carbapenemasas tipo KPC y se identificaron otros tipos de carbapenemasas como Sme en Serratia marcescens, NDM en Providencia reltgeri, OXA-163 en Klebsiella pneumoniae y OXA-Aci en Acinetobacter sp., destacando la importancia y la necesidad de la implementación de técnicas confirmatorias de carbapenemasas en los laboratorios de bacteriología.

Palabras claves: Enterobacteria, carbapenemasa, Blue Carba, Triton Hodge Test, $\mathrm{mCim}$

\section{Introducción}

En los últimos años se ha producido una gran alarma y preocupación por la gran dispersión de los bacilos gramnegativos resistentes a los carbapenémicos en los que el mecanismo implicado es la producción de betalactamasas capaces de hidrolizar este grupo de antimicrobianos y que se han asociado a elementos genéticos transferibles. Estas enzimas se denominan genéricamente carbapanemasas y tienen un directo impacto en la disponibilidad de alternativas terapéutica (Jorge Calvo et al. Sociedad Española de Enfermedades Infecciosas y Microbiología Clínica. 2011).

Las carbapenemasas se agrupan en las diferentes clases moleculares de Ambler que se corresponden con diferentes grupos funcionales de la clasificación de Bush y Jacoby del año 2010. Dentro de las clases moleculares, las de las clases A y D son serina-beta-lactamasas (KPC, Sme, OXA), mientras que las de clase $\mathrm{B}$, son metalo-beta-lactamasas (MBLs), es decir, su actividad hidrolítica depende de la presencia de zinc. Dentro de las Serin-beta-lactamasas, grupo $2 \mathrm{f}$ de K. Bush, se encuentran las enzimas del tipo KPC, Sme (en el caso de Serratia marcescens), NMC-A e IMI, pero la más importante clínicamente de este grupo son las KPC, de naturaleza plasmídica y que hidrolizan eficientemente a todos los antibióticos beta-lactámicos (incluyendo el AZT) y se inhiben por ácido fenilborónico, mientras que las MBLs de clase B y correspondiente al grupo $3 \mathrm{a}$ de K. Bush no hidrolizan a los monobactámicos (aztreonam), $y$ se inhiben por quelantes del zinc (EDTA y ácido dipicolínico).

Entre las de clase D, las oxacilinasas, también denominadas de tipo OXA, tiene la particularidad fenotípica de no afectar a los monobactámicos y presentan una baja eficiencia hidrolítica frente cefalosporinas de tercera y de cuarta generación y frente a las carbapenemas, por lo que en muchas ocasiones aparecen como sensibles a estos antimicrobianos. Sin embargo, hace poco tiempo, se descubrió una variante distinta existente en la Argentina, denominada OXA-163, la cual pasó a ser un grave problema en la salud, debido a que tiene actividad hidrolítica sobre las cefalosporinas de tercera y cuarta generación y los monobactam. Para detectarlas, se analiza la sensibilidad con Ertapenem y halo de inhibición de tazobactam.

La detección de carbapenemasas supone un reto para los laboratorios de Mi- 
crobiología Clínica. Requiere un análisis pormenorizado del antibiograma y de la sensibilidad a todos los beta-lactámicos, la implementación con métodos fenotípicos de cribado y la confirmación mediante detección de la hidrólisis del carbapenem, la inhibición de la actividad de la enzima con inhibidores específicos y la diferenciación del tipo de carbapenemasa mediante métodos moleculares basados principalmente en técnicas de PCR. Por tanto, es necesario establecer una metodología que facilite su detección (Bou G, Vila J, Seral C, Casti1lo FJ. Detection of carbapenemase-producing Enterobacteriaceae in various scenarios and health settings. Enferm Infecc Microbiol Clin 2014; 32 (Supl 4):24-32.).

\section{Metodología}

Se estudiaron 386 muestras clínicas de pacientes atendidos en el Hospital Escuela "Gral. José de San Martín", Ciudad de Corrientes, durante el mes de agosto del 2018.

Coloraciones: Se realizó coloración de Gram a los extendidos de cada muestra clínica.

Medios de Cultivos: Cada muestra clínica se sembró en los siguientes medios de cultivos: Levine; CLDE (Cistina - Lactosa - Deficiente en electrolitos); CHROMagarTM mSuperCARBATM (Medio cromogénico para la detección y aislamiento de bacterias productoras de carbapenemasas); tioglicolato con indicador (medio de enriquecimiento líquido); Muller Hinton y Muller Hinton con agregado de Tween (THT).
Pruebas de identificación bacteriana: A partir de colonias de Enterobacterias aisladas en los medios Levine y CLDE, se realizaron las pruebas de identificación TSI (medio agar hierro tres azúcares), Citrato, SIM (movilidad, Indol y producción de SH2), LIA (Lisina Hierro Agar), Urea y Ornitina descarboxilasa. A las colonias sospechosas de Bacilos Gram (-) No Fermentadores (BNF) se utilizaron para su identificación Oxidasa, Motilidad, Arginina, Lisina, Ornitina y DNASA.

Antibiogramas: Se utilizó el método Kirby-Bauer (antibiograma por difusión de discos en agar) para determinar la sensibilidad del agente microbiano frente a un antibiótico. Se basa en la formación de halos de inhibición del crecimiento bacteriano, en una placa inoculada homogéneamente con el microorganismo en estudio. Se midieron los halos generado y se comprobó la efectividad del antibiótico comparando los valores del diámetro del halo con las tablas CLSI. Se visualizaron los efectos inhibitorios (efecto "huevo") producidos por el ácido borónico (en el caso de la presencia de carbapenemasas tipo KPC), o los efectos inhibitorios por EDTA (en el caso de la presencia de carbapenemasas tipo MBL).

Métodos de detección de carbapenemasas: Se utilizaron los protocolos descritos por el Servicio Antimicrobianos, Laboratorio Nacional de Referencia en Antimicrobianos, INEI-ANLIS "Dr. Carlos G. Malbrán". 
- $B L U E$ CARBA: "Detección rápida de carbapenemasas". En dos tubos de eppendorf se colocaron $200 \mathrm{ul}$ de solución fisiológica $(\mathrm{NaCl}$ al $0.9 \%)$ a $\mathrm{pH} 8,5$ y en cada uno de ellos se agrega, con un ansa, la cepa a estudiar hasta una turbidez de 2 en la escala de Mc Farland. Se agita con vórtex durante 1 minuto y se deja reposar a temperatura ambiente durante 30 minutos para la liberación de las carbapenemasas. A uno de los tubos (tubo control) se le agrega la tableta de "CARB Negative Control Blue" $y$ al otro tubo (tubo de reacción) se le agrega la tableta de "imipenem $(2 \mathrm{x})+\mathrm{Br}$. Thymol". Se incubaron a $35^{\circ} \mathrm{C}$ por un máximo de 2 horas y finalmente se observó el cambio de color. Se interpretó positivo para carbapenemasas cuando el tubo de reacción viró al verde o amarillo/blanco y el tubo de control mantuvo el color azul.

- TRITON HODGE TEST (THT):

"Detección de carbapenemasas mediante test de Hodge mejorado". Se agregó 50 microlitros de Triton X-80 en la superficie de la placa de MHA y se distribuyó mediante un hisopo hasta su absorción completa. Se eliminó la humedad superficial de la placa por evaporación a $35^{\circ} \mathrm{C}$. Se realizó una suspensión de turbidez equivalente al 0.5 Mac Farland de la cepa E. coli ATCC 25922 y se hisopo la placa. Se colocó en el centro de la placa un disco de meropenem y con un ansa estéril se tomó de 3 a 5 colonias de un cultivo fresco de la muestra en estudio y se realizó una estrió desde el borde del disco hacia la periferia de la placa. Se incubó la placa en aerobiosis a $35^{\circ} \mathrm{C}$ durante $16-18$ hs.
Se interpretó de la siguiente manera: sobrecrecimiento de la cepa indicadora hacia el disco de carbapenem en la intersección de la estría con la zona de inhibición (THT positivo); la zona de inhibición inalterada en su intersección con la estría de la cepa incógnita (THT negativo); zona clara a lo largo de la estría de la cepa incógnita (THT indeterminado).

- mCIM: "Método modificado de inactivación de carbapenemasas". Con un ansa de $10 \mu \mathrm{L}$ se tomó la cepa incógnita y se resuspendió en $2 \mathrm{~mL}$ de caldo TSA; de forma inmediata se sumergió un disco de Meropenem (MEM) 10 $\mu \mathrm{g}$ dentro de la suspensión y se incubó durante 4 horas a $35^{\circ} \mathrm{C}$. Luego se retiró el disco con pinza estéril para ser colocado sobre una placa de agar Mueller-Hinton previamente hisopada con la cepa E.coli ATCC 25922 a una turbidez de 0,5 McFarland.. Se incubó a $35^{\circ} \mathrm{C}$ durante 18-20horas. La interpretación se basó en la medición de los halos de inhibición: Positivo para carbapenemasas (halo entre 6-15mm) y Negativo para carbapenemasas (halo mayor a $19 \mathrm{~mm}$ ).

\section{Resultados}

De un total de 386 muestras clínicas que ingresaron en el Hospital Escuela "Gral. José F. de San Martín" durante el mes de agosto de 2018, se identificaron 70 Enterobacterias $(18,13 \%)$ y 25 Bacilos Gram (-) no fermentadores $(6,48 \%)$, observándose su distribución en el siguiente gráfico (gráfico No1): 


\section{Microorganismos identificados}

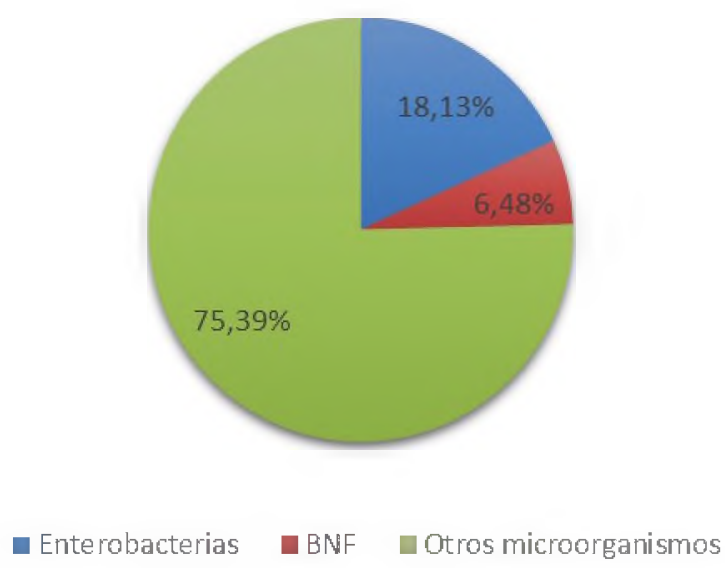

Gráfico No 1: Microorganismos identificados

Del total de Enterobacterias identifica- el 7.14\% son del tipo Sme, el 1.43\% corresdas, el 30\% son productores de carbapene- ponden al tipo NDM y el $1.43 \%$ restando masas, de los cuales el 20\% son tipo KPC, al tipo OXA-163 (gráfico n²).

\section{Enterobacterias productoras de carbapenemasas}

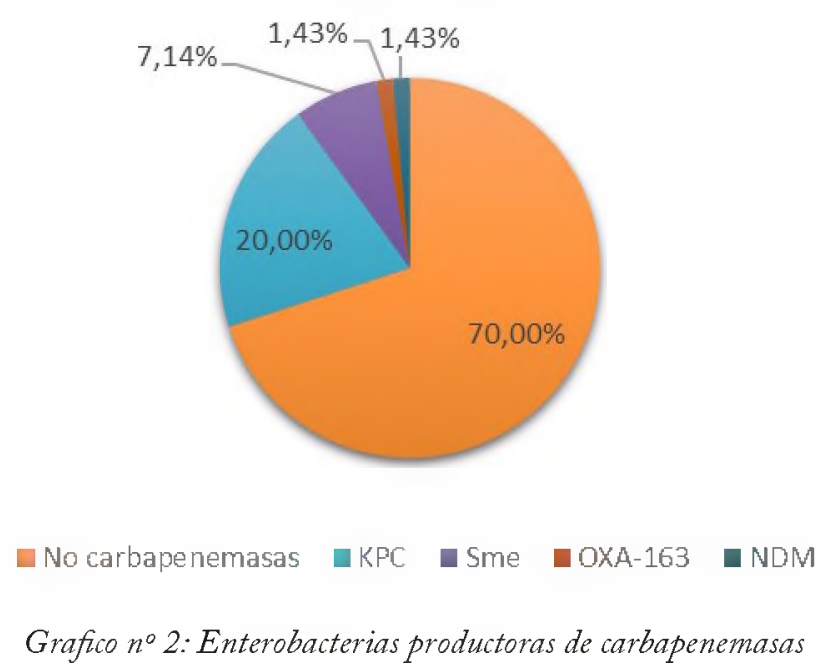

Dentro de las enterobacterias productoras de carbapenemasas del tipo KPC identificadas, $54.14 \%$ correspondió a colonizaciones del tracto rectal y $45.86 \%$ a infecciones.
Con respecto a los Bacilos No fermentadores identificados, el $40 \%$ son Pseudomonas aeruginosa, el 8\% Stenotrophomona maltophilia y el 52\% restante Acinetobac- 
ter spp. De ésta última todas fueron pro- (Gráfico No 3 ). ductoras de carbapenemasas tipo OXA-Aci

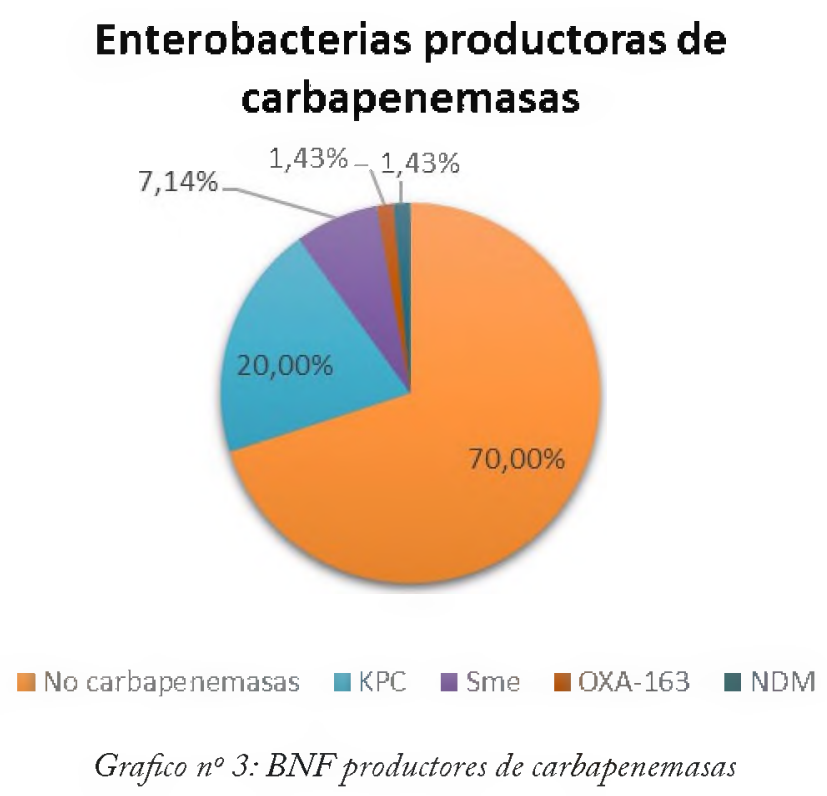

\section{Discusión}

En el Hospital Escuela "Gral. José F. de San Martín", Ciudad de Corrientes, se obtuvo, durante el mes de agosto del 2018, un importante porcentaje de Enterobacterias productoras de carbapenemasas tipo KPC, correspondiente a un $20 \%$ del total de las Enterobacterias identificadas, de las cuales $45.86 \%$ fueron productoras de infecciones y el resto fueron colonizaciones del tracto rectal. Además, se identificaron otros tipos de carbapenemasas como Sme en Serratia marcescens, NDM en Providencia reltgeri y OXA-163 en Klebsiella pneumoniae.

También se identificó carbapenemasas en Bacilos no fermentadores, de tipo OXAAci, hallandosé en un $100 \%$ de las Acinetobacter spp identificadas. En Pseudomonas aeruginosa, no se identificó mecanismos de resistencia a antibióticos.

Dentro de los métodos de detección de carbapenemasas, el método microbiológico THT es el más confiable, ya que resultó positivo en todos los tipos de carbapenemasas. En cambio, con el método de screening Carba Blue, se obtuvo falso negativo en el caso de las OXA-163. Con respecto al método mCIM, sirvió únicamente para las enterobacterias, no así para los BNF, en los cuales se obtuvieron resultados falsos negativos ante la presencia de carbapenemasas.

Cabe destacar, la identificación de una cepa Klebsiella pneumoniae productora de carbapenemasa de tipo OXA-163, no antes hallada en el Hospital Escuela "Gral. José F. de San Martín" de la Ciudad de Corrientes. El método de screening Carba Blue fue 
negativo, pero sin embargo el THT fue positivo, observándose previamente en el antibiograma IMI sensible, MER intermedio, ERT resistente, acompañados con PTZ Resistente sin ningún tipo de inhibición con ác. Borónico y con EDTA, y finalmente confirmado con el K-Set.

\section{Conclusiones}

Finalmente se logró determinar el porcentaje de bacilos Gram (-) productores de carbapenemasas en infecciones y colonizaciones de adultos que concurrieron al Hospital Escuela "Gral. Jose Fco. de San Martìn" de la ciudad de Corrientes durante el mes de agosto del 2018, y se contribuyó con datos estadísticos en la región del hospital.

Se destacó la importancia y la necesidad de la implementación de técnicas confirmatorias de carbapenemasas en los laboratorios de bacteriología, como es el método THT, un método de fácil realización y de bajo costo, debido a que los métodos de screening dan falsos negativos, y "no detectar una carbapenemasa en una muestra clínica aumenta un 20-40\% la mortalidad del paciente" (Pasteran F. Curso "Enterobacterias productoras de carbapenemasa". 2017).

\section{Bibliografía}

- Daikos G, Tsaousi S, Leonidas S, Tzouvelekis I, Loannis A. Carbapenemase-producing Klebsiella pneumoniae Bloodstream infections: Lowering Mortality by Anti- biotic Combination Schemes and the Role of Carbapenems. Antimicrob. Agents Chemother.2014, 58: 2322.

- Drusano GL. From lead optimization to NDA approval for a new antimicrobial: use of pre-clinical effect models and pharmacokinetic/pharmacodynamic mathematical modeling. Bioorg Med Chem 2016; 24:6401-8.

- Papp-Wallace KM, Bonomo RA. New $\beta$-lactamase inhibitors in the clinic. Infect Dis Clin North Am 2016; 30:441-64.

- Pasteran F. Curso "Enterobacterias productoras de carbapenemasa". 2017. en https:// youtu.be/yi9EZkPxMbs

- Pittet D, Tamara D, Wenzel R. Nosocomial bloodstream infection in critically ill patients: excess length of stay, extra cost, and attibutable mortality. JAMA. 271: 15981601.1994.

- Poirel L, Potron A, Nordmann P. OXA-48like carbapenemases: the phantom menace. J Antimicrob Chemother 2012; 67:1597-606.

Potron A, Poirel L, Dortet L, Nordmann P. Characterisation of OXA-244, a chromosomally-encoded OXA-48-like $\beta$-lactamase from Escherichia coli. Int $\mathrm{J}$ Antimicrob Agents 2016; 47:102-3. 8- Nordmann P, Poirel L. The difficult-to-control spread of carbapenemase producers among Enterobacteriaceae worldwide. Clin Microbiol Infect 2014; 20:821-30

- Spellberg B, Bonomo RA. Editorial commentary: ceftazidime-avibactam and carbapenem-resistant Enterobacteriaceae: "We're gonna need a bigger boat." Clin Infect Dis 2016; 63:1619-21 